\title{
Visceral artery aneurysms: Incidence, management, and outcome analysis in a tertiary care center over one decade
}

\author{
Michael B. Pitton • Evelyn Dappa • Florian Jungmann • Roman Kloeckner • \\ Sebastian Schotten • Gesine M. Wirth • Jens Mittler • Hauke Lang • \\ Peter Mildenberger $\cdot$ Karl-Friedrich Kreitner $\cdot$ Katja Oberholzer $\cdot$ Christoph Dueber
}

Received: 26 June 2014 / Revised: 10 November 2014 / Accepted: 13 January 2015 / Published online: 19 February 2015

(C) The Author(s) 2015. This article is published with open access at Springerlink.com

\begin{abstract}
Objectives To evaluate the incidence, management, and outcome of visceral artery aneurysms (VAA) over one decade. Methods 233 patients with 253 VAA were analyzed according to location, diameter, aneurysm type, aetiology, rupture, management, and outcome.

Results VAA were localized at the splenic artery, coeliac trunk, renal artery, hepatic artery, superior mesenteric artery, and other locations. The aetiology was degenerative, iatrogenic after medical procedures, connective tissue disease, and others. The rate of rupture was much higher in pseudoaneurysms than true aneurysms (76.3\% vs.3.1\%). Fifty-nine VAA were treated by intervention $(n=45)$ or surgery $(n=14)$. Interventions included embolization with coils or glue, covered stents, or combinations of these. Thirty-five cases with ruptured VAA were treated on an emergency basis. There was no difference in size between ruptured and nonruptured VAA. After interventional treatment, the 30-day mortality was $6.7 \%$ in ruptured VAA compared to no mortality in non-ruptured cases. Follow-up included CT and/or MRI after a mean period of $18.0 \pm 26.8$ months. The current status of the patient was obtained by a structured telephone survey.

Conclusions Pseudoaneurysms of visceral arteries have a high risk for rupture. Aneurysm size seems to be no reliable predictor for rupture. Interventional treatment is safe and effective for management of VAA.
\end{abstract}

M. B. Pitton $(\bowtie) \cdot$ E. Dappa $\cdot$ F. Jungmann $\cdot$ R. Kloeckner $\cdot$

S. Schotten $\cdot$ G. M. Wirth $\cdot$ P. Mildenberger $\cdot$ K.-F. Kreitner $•$

$\mathrm{K}$. Oberholzer $\cdot$ C. Dueber

Department of Diagnostic and Interventional Radiology, University

Hospital of Mainz, Langenbeckstr.1, 55131 Mainz, Germany

e-mail: michael.pitton@unimedizin-mainz.de

J. Mittler $\cdot$ H. Lang

Department of Abdominal, Visceral and Transplantation Surgery,

University Hospital of Mainz, Langenbeckstr.1,

55131 Mainz, Germany
Key Points

- Diagnosis of visceral artery aneurysms is increasing due to CT and MRI.

- Diameter of visceral arterial aneurysms is no reliable predictor for rupture.

- False aneurysms/pseudoaneurysms and symptomatic cases need emergency treatment.

- Interventional treatment is safe and effective.

Keywords Visceral aneurysm · False aneurysm / Pseudoaneurysm $\cdot$ Ruptured aneurysm $\cdot$ Endovascular procedures $\cdot$ Outcome analysis

$\begin{array}{ll}\text { Abbreviations } \\ \text { VAA } & \text { Visceral artery aneurysm } \\ \text { SAA } & \text { Splenic artery aneurysm } \\ \text { HAA } & \text { Hepatic artery aneurysm } \\ \text { SMAA } & \text { Superior mesenteric artery aneurysm } \\ \text { CTRA } & \text { Coeliac trunc aneurysm } \\ \text { GDAA } & \text { Gastroduodenal artery aneurysm } \\ \text { PDAA } & \text { Pancreaticoduodenal artery aneurysm } \\ \text { RAA } & \text { Renal artery aneurysm } \\ \text { GAA } & \text { Gastric artery aneurysm } \\ \text { CT } & \text { Computed tomography }\end{array}$

\section{Introduction}

Visceral arterial aneurysms (VAAs) are a rare entity; they are often asymptomatic, incidental findings in computed tomography (CT) and magnetic resonance imaging (MRI). VAAs can present as life-threatening ruptures that require emergency treatment. However, discriminating between VAAs that are harmless incidental $\mathrm{CT}$ findings which do not require 
treatment and high-risk aneurysms is not always possible. Several publications recommend treatment of VAAs $>2 \mathrm{~cm}$ in diameter [1-5]. Nonetheless, clinical experience indicates that the risk of rupture depends not only on the aneurysm diameter, but also upon VAA localization [3]; underlying disease, such as congenital defects (e.g., Ehlers-Danlos Syndrome), atherosclerosis, and mycotic/inflammatory aneurysm [6-8]; and the rate of growth $[9,10]$. In contrast to true aneurysms, which feature distension of all three layers of the arterial wall, so-called false aneurysms or pseudoaneurysms result from a breach of the inner-wall layers, resulting in bulging of the adventitial layer. False aneurysms are often caused by iatrogenic trauma, e.g. after hepatobiliary or vascular surgery.

This retrospective study reviewed all cases of VAA seen at our university medical centre over a 10 -year period. Our objective was to characterize the incidence of VAA, identify possible risk factors for aneurysm rupture, and compare surgical and interventional-radiological approaches with respect to clinical outcome.

\section{Materials and methods}

For patient selection, we searched our institutional database (covering years 2000-2010) for the term 'aneurysm', which yielded 12,588 radiological reports, mostly related to aortic pathologies. A total of 233 patients were identified as having VAA. Information about patient age, sex, presenting symptoms and signs, diagnostic modalities, risk factors, co-morbidities, recent operations, and medication was obtained from medical records and office charts. Data were analysed according to anatomic features, such as aneurysm location and diameter, true or false aneurysm, and aneurysm status (ruptured or non-ruptured). The aetiology of each aneurysm was retrospectively deduced and analysed from the underlying diseases documented in the patients' records, previous medical procedures, and from clinical findings at admission.

Clinical management of the patients was investigated in terms of surgical therapy, interventional treatment and watchful waiting. The specific type of surgical and interventional technique was obtained from medical reports and from imaging.

The clinical course of the patients was investigated by means of a structured telephone survey of all patients or their relatives and of their general medical practitioners. The survey included all available information on successive hospital stays, surgical or interventional treatment, and current clinical condition.

\section{Results}

We identified 233 patients (age $65 \pm 13$ years [range 17-95 years], 142 men and 91 women) diagnosed with a total of
253 VAAs over the course of a decade (Table 1). In the majority of cases VAA involved the splenic artery $(n=83)$, followed by the coeliac trunk $(n=47)$, the renal arteries $(n=$ $44)$, the hepatic artery $(n=40)$, the superior mesenteric artery and its branches $(n=17)$, the gastroduodenal artery $(n=10)$, the pancreaticoduodenal artery $(n=8)$, the gastric artery $(n=$ 4 ), and combinations of these as listed in Table 2. Thirty-seven aneurysms in 35 patients presented with rupture; the majority of aneurysms were detected in a non-ruptured condition ( $n=$ 216 aneurysms). Over $90 \%$ of the aneurysms ( $n=231$ in 212 patients) were detected by CT scans, followed by angiography ( $n=13$ in 12 patients) and MRI ( $n=9$ in 9 patients). Radiological follow-up was $18.0 \pm 26.8$ months (range: 1 day to 109 months).

Sixty-two of the 233 patients ( $26.6 \%$ ) presented with specific symptoms upon admission to hospital, and all 35 patients with ruptured aneurysms showed symptoms. A reduced haemoglobin count of $8.2 \pm 1.6 \mathrm{~g} / \mathrm{dl}$ in 34 of 62 patients $(54.8 \%)$ was the most frequent sign of rupture. Eleven of 62 symptomatic patients $(17.7 \%)$ presented with abdominal pain. For a summary of the patients' clinical presentation, see Table 3.

One hundred and seventy-one of the 233 patients (73.4\%) had no specific symptoms. In 13 asymptomatic patients, a VAA was already known from previous examinations. Of the 171 asymptomatic patients, 158 (92.4\%) were incidentally diagnosed with a VAA. Indications for imaging in patients with incidental findings included follow-up examinations after tumour treatment or other medical conditions $(n=91)$, suspected illness unrelated to the VAA $(n=44)$, tumour staging $(n=20)$, and preoperative imaging $(n=3)$.

According to the retrospective rating described above, the main aetiology of VAA was degenerative atherosclerosis (197 of 253 aneurysms; $77.9 \%$ ), with varying degrees of calcification of the arteries. Moreover, there were 13 post-stenotic aneurysms, with arterial stenosis of the coeliac trunk or its tributaries and stenosis of the superior mesenteric artery (Table 2). The second most frequent aetiology was diverse complications after preceding medical procedures, with 23 iatrogenic false aneurysms of the hepatic artery or its tributaries as well as the renal artery. The remaining VAAs developed in patients with vasculitis due to connective tissue diseases, hereditary diseases like Ehlers-Danlos syndrome, fibromuscular dysplasia, and hereditary haemorrhagic telangiectasia. Seven VAAs occurred secondary to inflammatory diseases, such as pancreatitis. Rare causes for VAA included trauma, tumours and mycotic aneurysms after infection (e.g., endocarditis).

A total of 196 pathologies were rated as true aneurysms, compared to 38 false aneurysms. The remaining 19 aneurysms could not be clearly assigned to one of these two groups and were therefore labelled as indeterminable aneurysms. These aneurysms were caused either by infection or diseases of the 
Table 1 Patient characteristics

January 2000-August 2010

\begin{tabular}{ll}
\hline Patients (n) & 233,142 men, 91 women \\
Age (years) & $65 \pm 13$ (range 17-95) \\
Aneurysms & 253 \\
Ruptured aneurysms & 37 in 35 patients \\
Non-ruptured aneurysms & 216 in 198 patients \\
Diameter (mm) & $16.1 \pm 9.8$ (range 4.0-111.9) \\
Follow-up via telephone (months) & $51.0 \pm 32.1(43$ median, Q1/Q3 25/69) \\
Follow-up imaging (months) & $18.0 \pm 26.8(7$ median, Q1/Q3 1/19.75) \\
Co-morbidities & $\mathrm{n}(\%)$ \\
Arterial hypertension & $126(54.1)$ \\
Diabetes mellitus type 2 & $35(15.0)$ \\
Smoker & $41(17.6)$ \\
Coronar heart disease & $37(15.9)$ \\
Aortic aneurysm & $26(11.2)$ \\
HCC & $18(7.7)$ \\
Colon carcinoma & $13(5.6)$ \\
Melanoma & $8(3.4)$ \\
Rheumatoid arthritis & $7(3.0)$ \\
COPD & $7(3.0)$ \\
Liver cirrhosis & $29(12.5)$ \\
Portal hypertension & $12(5.2)$ \\
Chronic renal failure & $21(9.0)$ \\
Renal cysts & $8(3.4)$ \\
Pregnancy & $0(0)$ \\
\hline
\end{tabular}

connective tissue, which are known to cause both true as well as false aneurysms (11-20). Since no histological information was available that would allow us to reliably classify these aneurysms as true or false, we decided to analyse them separately in order to minimize any bias. For an overview of the incidence and location of true, false and indeterminable aneurysms, see Fig. 1.

Thirty-seven of 253 VAAs (14.6\%) presented with aneurysm rupture (Table 4). The majority of ruptured aneurysms were pseudoaneurysms $(n=29)$. True VAAs presented with a rupture rate of $3.1 \%$ (six out of 196 aneurysms). Vice versa, false VAAs had a significantly higher rupture rate of $76.3 \%$ ( 29 of 38 aneurysms). There was evidence of rupture of indeterminable VAAs in two cases.

The mean overall size of the VAAs was $16.1 \pm 9.8 \mathrm{~mm}$, with a wide range of diameters $(4.0-111.9 \mathrm{~mm})$, which varied depending upon VAA localization (Table 4). There was no significant difference between the diameters of ruptured aneurysms compared to non-ruptured aneurysms $(14.8 \pm 8.2 \mathrm{~mm}$ vs. $16.3 \pm 10.0 \mathrm{~mm}$, respectively). However, in 18 cases, the aneurysm size could not be determined, because the aneurysm rupture prevented delineation and reliable diameter measurement within the haematoma. The greatest diameters were found in splenic artery aneurysms (SAAs). The overall maximum diameter was up to $111.9 \mathrm{~mm}$ in a nonruptured SAA compared to $34.7 \mathrm{~mm}$ in a ruptured HAA. Excluding these outliers of diameters in both groups, the mean transverse diameter of non-ruptured and ruptured cases was nearly equal $(15.9 \pm 7.4 \mathrm{~mm}$ vs. $14.3 \pm 7.5 \mathrm{~mm}$, respectively). Moreover, there was no significant difference between the mean diameters of false aneurysms compared to true aneurysms $(15.6 \pm 7.6 \mathrm{~mm}$ vs. $16.3 \pm 10.3 \mathrm{~mm}$, respectively) (Table 4).

Specific aneurysm-targeted treatment was applied to 59 of the 253 VAAs ( $23.3 \%$ ) by means of interventional techniques $(n=45)$ or open surgery $(n=14)$ (Fig. 2$)$. Thirty-six VAAs with aneurysm rupture or contained rupture $(14.2 \%)$ were treated on an emergency basis. In one ruptured VAA, a spontaneous occlusion was observed during emergency angiography, which was confirmed in a postangiographic $\mathrm{CT}$. An additional 23 non-ruptured VAAs $(9.1 \%)$ were treated electively at the discretion of the interventional radiologist or surgeon based on individual findings (e.g., aneurysm growth or underlying disease); 13 by means of intervention and ten surgically. The remaining 193 cases were rated clinically harmless without suspicious symptoms and without need for immediate treatment; these cases were followed up by watchful waiting. 
Table 2 Aetiology of visceral arterial aneurysms

\begin{tabular}{|c|c|c|}
\hline Aetiology & $\begin{array}{l}\text { VAA } \\
\text { (patients) }\end{array}$ & \\
\hline Degenerative & $197(186)$ & $\begin{array}{l}\text { SAA (79), CTRA (45), RAA (27), HAA (23), } \\
\text { SMAA (11), GDAA (6), GAA (2), PDAA (4) }\end{array}$ \\
\hline VAA without calcification & $141(137)$ & $\begin{array}{l}\text { SAA (56), CTRA (34), RAA (22), HAA (19), } \\
\text { SMAA (6), GDAA (2), GAA (1), PDAA (1) }\end{array}$ \\
\hline VAA with calcification & $43(38)$ & $\begin{array}{l}\text { SAA (23), CTRA (8), RAA (5), HAA (4), } \\
\text { SMAA (2), GAA (1) }\end{array}$ \\
\hline Post-stenotic VAA & $13(11)$ & GDAA (4), CTRA (3), SMAA (3), PDAA (3) \\
\hline Medical procedures & $23(23)$ & HAA (15), RAA (6), GDAA (1), PDAA (1) \\
\hline Operation & $14(14)$ & HAA (11), RAA (2), GDAA (1) \\
\hline Pancreaticoduodenectomy & $5(5)$ & HAA (5) \\
\hline Haemihepatectomy & $3(3)$ & HAA (2), GDAA (1) \\
\hline Liver transplantation & $3(3)$ & HAA (3) \\
\hline Nephrectomy & $1(1)$ & RAA (1) \\
\hline Renal cyst enucleation & $1(1)$ & RAA (1) \\
\hline Biliodigestive anastomosis & $1(1)$ & HAA (1) \\
\hline Other intervention & $9(9)$ & HAA (4), RAA (4), PDAA (1) \\
\hline $\begin{array}{l}\text { Percutaneous transhepatic biliary } \\
\text { drainage }\end{array}$ & $2(2)$ & HAA (2) \\
\hline Renal biopsy & $2(2)$ & RAA (2) \\
\hline Hepatic biopsy & $1(1)$ & HAA (1) \\
\hline Nephrostoma & $1(1)$ & RAA (1) \\
\hline Percutaneous nephrolithotripsy & $1(1)$ & RAA (1) \\
\hline Selective internal radiation therapy & $1(1)$ & HAA (1) \\
\hline Gastroduodenoscopy & $1(1)$ & PDAA (1) \\
\hline Connective tissue disosrder & $17(9)$ & $\begin{array}{l}\text { RAA (7), SMAA (5), PDAA (2), GDAA (1), } \\
\text { HAA (1), SAA (1) }\end{array}$ \\
\hline Vasculitis & $7(4)$ & SMAA (3), PDAA (2), GDAA (1), RAA (1) \\
\hline Ehlers-Danlos & $6(1)$ & RAA (3), HAA (1), SAA (1), SMAA (1) \\
\hline Fibromuscular dysplasia & $3(3)$ & RAA (3) \\
\hline Osler disease & $1(1)$ & SMAA (1) \\
\hline Inflammation & $7(6)$ & GAA (2), GDAA (2), SAA (2), RAA (1) \\
\hline Trauma & $5(5)$ & CTRA (2), SAA (1), PDAA (1), RAA (1) \\
\hline Tumour & $2(2)$ & RAA (2) \\
\hline Infection, mycotic aneurysm & $2(2)$ & HAA (1), SMAA (1) \\
\hline
\end{tabular}

$S A A$ splenic arterial aneurysm, $H A A$ hepatic arterial aneurysm, $S M A A$ superior mesenteric artery aneurysm, CTRA coeliac trunk aneurysm, GDAA gastroduodenal artery aneurysm, $P D A A$ pancreaticoduodenal artery aneurysm, $R A A$ renal artery aneurysm, GAA gastric artery aneurysm
There was no periprocedural mortality after radiological intervention or open surgery. The 30-day mortality after interventional treatment of VAA was in total $5 \%(n=2$ of 40 patients), one patient after coil embolization and the other after stent grafting. Since both deaths occurred in the emergency setting, the mortality was $6.7 \%(n=2$ of 30 patients) in this subgroup. There was no 30-day mortality in the 11 patients who underwent open surgery; however, due to the small number of cases, we were unable to make comparisons with the interventional group or draw conclusions. For further details concerning the management of VAA, see Table 5.

The overall rate of periprocedural complications after interventional treatment was $12.5 \%$ (five complications in only an accompanying pathology (Fig. 2). 
Table 3 Specific symptoms at admittance to hospital

\begin{tabular}{|c|c|c|c|c|}
\hline \multirow[t]{2}{*}{ Specific signs or symptoms } & \multicolumn{2}{|c|}{ Symptomatic patients } & \multicolumn{2}{|c|}{ Symptomatic patients with ruptured VAA } \\
\hline & $\mathrm{n}$ (pat) & Localization & $\mathrm{n}$ (pat) & Localization \\
\hline Reduced haemoglobin count & $34^{*}$ & $\begin{array}{r}\text { HAA (15), RAA (8), GDAA (4), } \\
\text { SAA (4), PDAA (2), GAA (1) }\end{array}$ & 33 & $\begin{array}{r}\text { HAA (15), RAA (7), GDAA (4), } \\
\text { SAA (4), PDAA (2), GAA (1) }\end{array}$ \\
\hline Abdominal pain & 11 & $\begin{array}{l}\text { CTRA (4), SMAA (2), GAA (1), } \\
\text { HAA (1), PDAA (1), RAA (1), } \\
\text { SAA (1), }\end{array}$ & 1 & SMAA (1) \\
\hline Reduced general condition & $4^{* *}$ & CTRA (3), GDAA (1) & & \\
\hline Vomiting & 3 & SAA (2), HAA (1) & & \\
\hline Chest pain & 2 & RAA (2) & & \\
\hline Dyspnoea & 2 & SAA (2) & & \\
\hline Fever & 2 & CTRA (1), SAA (1) & & \\
\hline Cholangitis & 1 & SAA (1) & & \\
\hline Gastrointestinal bleeding & 1 & SAA (1) & & \\
\hline Severe arterial hypertension & 1 & SMAA (1) & & \\
\hline Urinary retention & 1 & RAA (1) & 1 & RAA (1) \\
\hline Total & 62 & $\begin{array}{l}\text { HAA (17), RAA (12), SAA (12), } \\
\text { CTRA (8), GDAA (5), SMAA (3), } \\
\text { PDAA (3), GAA (2) }\end{array}$ & 35 & $\begin{array}{l}\text { HAA (15), RAA (8), GDAA (4), } \\
\text { SAA (4), PDAA (2), GAA (1), } \\
\text { SMAA (1) }\end{array}$ \\
\hline
\end{tabular}

* 17 patients with a combination of symptoms including reduced haemoglobin count + abdominal pain $(\mathrm{n}=4)$, bleeding from drainages after surgery $(\mathrm{n}=$ $4)$, fever $(n=2)$, gross haematuria $(n=1)$, gross haematuria + fever $(n=1)$, vomiting $(n=1)$, multiple septic infarcts $(n=1)$, cholangitis $(n=1)$, chronic anaemia $(n=1)$, melaena $(n=1)$

** 1 patient with a combination of symptoms: reduced general condition + melaena $(\mathrm{n}=1)$

$S A A$ splenic arterial aneurysm, HAA hepatic arterial aneurysm, SMAA superior mesenteric artery aneurysm, CTRA coeliac trunk aneurysm, GDAA gastroduodenal artery aneurysm, $P D A A$ pancreaticoduodenal artery aneurysm, $R A A$ renal artery aneurysm, $G A A$ gastric artery aneurysm

40 patients) including one patient with myocardial infarction (ruptured VAA), two splenic infarctions, one patient with parenchymal abscesses (liver), and one with intracerebral bleeding (ruptured VAA). Four of the five complications occurred in patients with a ruptured VAA. Secondary bleeding after interventional treatment occurred in five cases. After open surgery, two out of 11 patients $(18.2 \%)$ suffered from perioperative complications: one splenic abscess (ruptured VAA), and one insufficient anastomosis after venous bypass interponate (non-ruptured VAA). Secondary bleeding occurred in two patients after open surgery (one in a ruptured and one in a nonruptured VAA); Tables 6 and 7 summarize the complications that occurred after interventional and surgical treatment, respectively. Patients with VAA who were stratified for watchful waiting had a 30-day mortality of $6.6 \%(12$ of 182 patients), without any death caused by verified aneurysm rupture.

Cross-sectional imaging was available for 143 of 233 patients $(61.4 \%)$ and comprised CT and/or MRI at a mean follow-up of $18.0 \pm 26.8$ months. The current status of the patients was obtained by a structured telephone survey conducted a mean of $51.0 \pm 32.1$ months after treatment. The survey yielded conclusive information for 228 of 233 patients.
The structured interview inquired about the patients' health, current medication and past hospital stays. Only five patients were lost to follow-up, resulting in high-quality data with a completion rate of $97.9 \%$. Of the 228 patients included in the follow-up, $161(70.6 \%)$ were alive and $67(29.4 \%)$ were deceased. Causes of death were progressive tumour $(n=33)$, cardiovascular events $(n=12)$, post-transplantation complications $(n=6)$, infection $(n=5)$, liver cirrhosis $(n=1)$, renal insufficiency $(n=2)$, complications of insufficient hepaticojejunostomy $(n=1)$, complications of systemic lupus erythematosus $(n=1)$, appendicitis $(n=1)$, intracerebral bleeding after double antiplatelet therapy 30 days after insertion of a stent graft for a ruptured HAA $(n=1)$, and gastrointestinal bleeding without clinical evidence of VAA rupture $(n=1)$. Moreover, there were three inconclusive deaths, including two patients with renal artery aneurysm (RAA) and SAA, which were conservatively treated. The third patient received a venous bypass for RAA and died 7 years after the procedure. Retrospectively, it remained unclear whether any of these inconclusive deaths were related to VAA complications.

Seventeen of the 161 remaining patients $(10.6 \%)$ suffered from some sort of abdominal complaint during follow-up; these were related to cholangitis $(n=2)$, duodenal ulcers $(n=$ $2)$, gallstones $(n=2)$, splenic infarction $(n=2)$, reflux 
Fig. 1 Incidence and localization of true, false and indeterminable aneurysms. $S A$ splenic arterial aneurysm, $H A$ hepatic arterial aneurysm, $S M A$ superior mesenteric artery aneurysm, $C T$ coeliac trunk aneurysm, $G D A$ gastroduodenal artery aneurysm, $P D A$ pancreaticoduodenal artery aneurysm, $R A$ renal artery aneurysm, $G A$ gastric artery aneurysm
True Aneurysms $(n=196)$

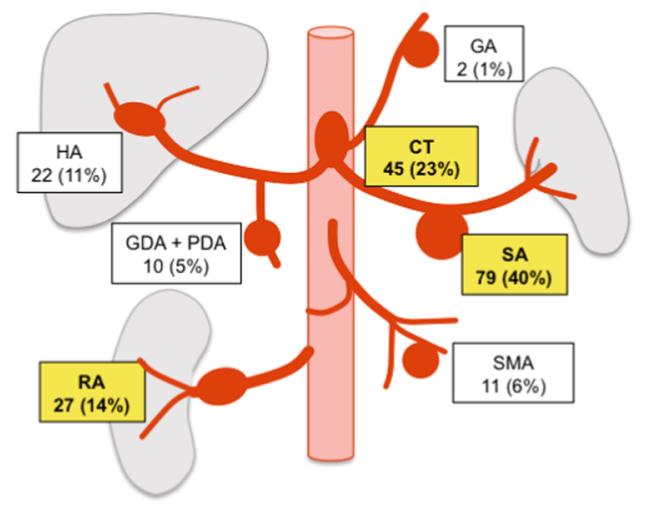

Indeterminable Aneurysms ( $\mathrm{n}=19)$

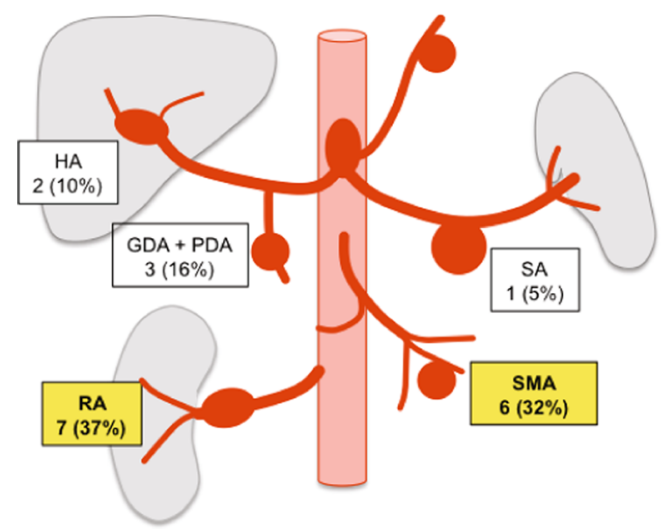

False Aneurysms ( $n=38)$

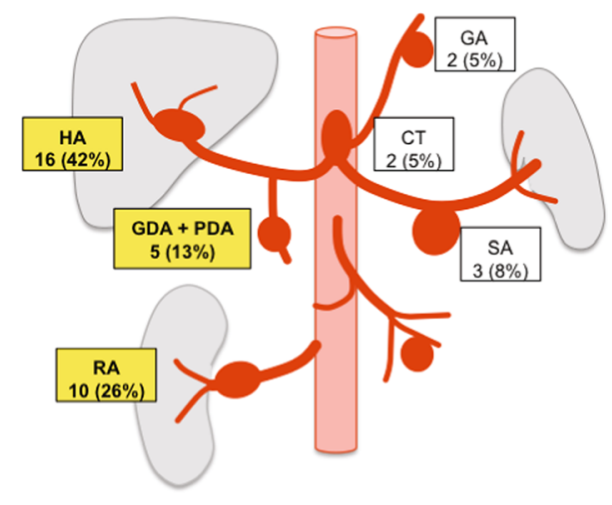

oesophagitis $(n=2)$, colitis $(n=1)$, chronic pancreatitis $(n=1)$, and chronic type B aortic dissection $(n=1)$. Four patients had abdominal complaints due to unknown causes $(n=4)$.

\section{Discussion}

The purpose of this study was to investigate the incidence, aetiology and current management of VAA at our university medical centre. The overall incidence of VAA was relatively low, with a total of 233 patients presenting with 253 VAAs over a 10-year period. The most frequent aetiology was degenerative/ atherosclerotic, which accounted for more than two-thirds of all cases. The second most frequent aetiology was complications after preceding medical procedures, with a $9.1 \%$ rate of iatrogenic false aneurysms. Vasculitis and diverse specific connective tissue disease were uncommon causes of VAA [11-19].

The prevalence of VAA is reported to be $0.1-2 \%[20,21]$; however, the number of undetected VAAs may be much higher. The clinical presentation is nonspecific in most cases,

Table 4 Transverse diameter of ruptured and non-ruptured visceral artery aneurysms (VAAs)

\begin{tabular}{|c|c|c|c|c|c|c|c|c|}
\hline & \multicolumn{2}{|c|}{$\begin{array}{l}\text { All VAAs ( } \mathrm{n}=253 \text { in } 233 \\
\text { patients) }\end{array}$} & \multicolumn{2}{|c|}{$\begin{array}{l}\text { True VAAs ( } \mathrm{n}=196 \text { in } 186 \\
\text { patients) }\end{array}$} & \multicolumn{2}{|c|}{$\begin{array}{l}\text { False VAAs ( } \mathrm{n}=38 \text { in } 36 \\
\text { patients) }\end{array}$} & \multicolumn{2}{|c|}{$\begin{array}{l}\text { Indeterminable VAAs ( } \mathrm{n}=19 \text { in } 11 \\
\text { patients) }\end{array}$} \\
\hline & $\mathrm{n}(\%)$ & Size (mm) & $\mathrm{n}(\%)$ & Size (mm) & $\mathrm{n}(\%)$ & Size (mm) & $\mathrm{n}(\%)$ & Size (mm) \\
\hline All & $253(100)$ & $\begin{array}{l}16.1 \pm 9.8 \\
\quad(4.0-111.9)\end{array}$ & $196(100)$ & $\begin{array}{l}16.3 \pm 10.3 \\
\quad(4.0-111.9)\end{array}$ & $38(100)$ & $\begin{array}{l}15.6 \pm 7.6 \\
\quad(6.4-33.2)\end{array}$ & $19(100)$ & $\begin{array}{l}15.5 \pm 7.0 \\
\quad(7.3-34.7)\end{array}$ \\
\hline Non-ruptured VAAs & $196(77.5)$ & $\begin{array}{r}16.3 \pm 10.0 \\
\quad(4.0-111.9)\end{array}$ & $190(96.9)$ & $\begin{array}{l}16.4 \pm 10.4 \\
\quad(4.0-111.9)\end{array}$ & $9(23.7)$ & $\begin{array}{l}16.3 \pm 6.8 \\
(8.8-27.3)\end{array}$ & $17(89.5)$ & $\begin{array}{l}14.3 \pm 4.2 \\
\quad(7.3-20.5)\end{array}$ \\
\hline Ruptured VAAs & $37(22.5)$ & $\begin{array}{l}14.8 \pm 8.2 \\
\quad(6.0-34.7)\end{array}$ & $6(3.1)$ & $\begin{array}{l}9.0 \pm 2.0 \\
\quad(6.0-11.2)\end{array}$ & $29(76.3)$ & $\begin{array}{l}15.4 \pm 7.9 \\
(6.4-33.2)\end{array}$ & $2(10.5)$ & $\begin{array}{l}22.4 \pm 17.5 \\
\quad(10.0-34.7)\end{array}$ \\
\hline
\end{tabular}


Fig. 2 Treatment allocation

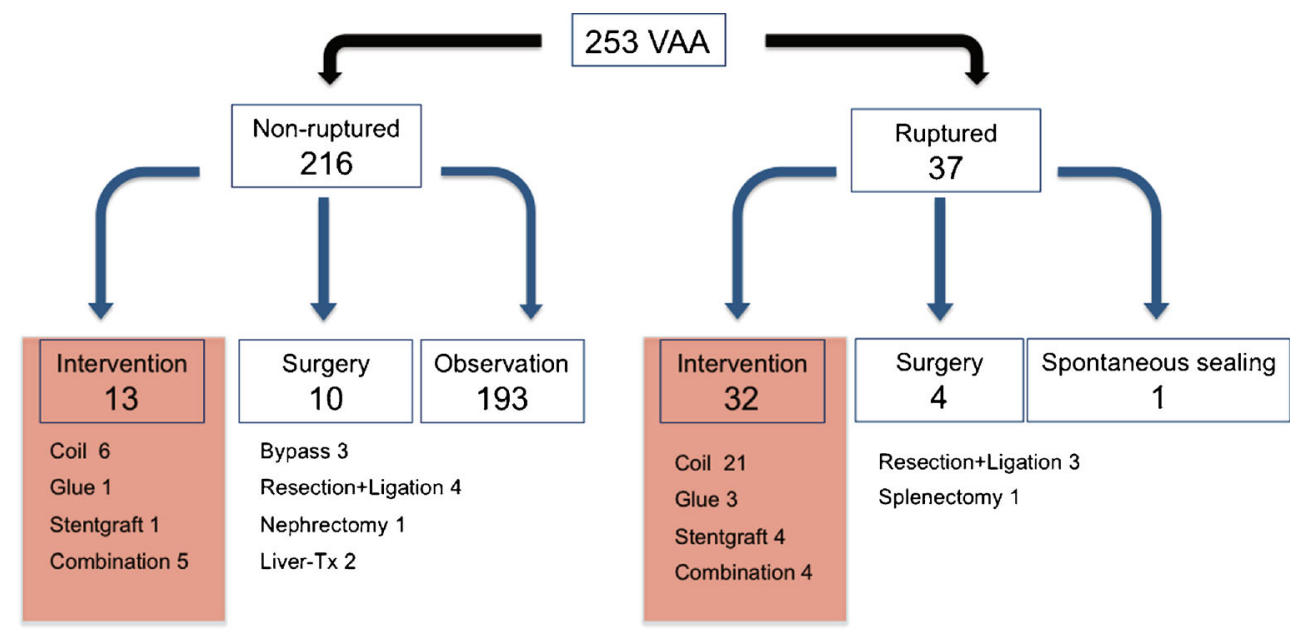

and the diagnosis of VAA is often an incidental finding. It is the general consensus that symptomatic VAA should be treated immediately, since rupture is associated with a high mortality rate $[9,22,23]$. A wide range of rupture rates have been reported [20-22, 24, 25], and emergency treatment of ruptured VAA has mortality rates of up to $30 \%[26,27]$. In our patients, VAA rupture resulted in intraperitoneal, retroperitoneal and gastrointestinal bleeding, as well as bleeding into adjacent organs. A striking number of VAA ruptures occurred after medical procedures. In our study, the 30-day mortality rate was comparably low in these cases; however, there was a considerable complication rate after interventional treatment and open surgery ( $12.5 \%$ and $18.2 \%$, respectively).

The decision to treat or not to treat asymptomatic VAA poses a challenge in elective cases [24, 27-30], and the treatment modality used varies based on location, clinical symptoms and co-morbidities $[24,28]$. There are no evidencebased data to rely on, and individual treatment decisions are based on clinicians' experience and the technical facilities of the interventional radiologist or surgeon. According to the guidelines, treatment is suggested for VAA with diameters $>2 \mathrm{~cm}$ or if the VAA is three times greater in diameter than the respective normal artery $[9,24,29]$. However, we did not find any difference in mean diameters between ruptured and non-ruptured aneurysms. Therefore, VAA diameter alone appears to be an inadequate criterion for decision making [24, $31,32]$. At our institution, treatment decisions for individual cases are based on an interdisciplinary discussion including the aetiology of the aneurysms and all clinical aspects of the particular case. To determine other possible risk factors, we tried to identify additional criteria. In our series, pseudoaneurysms presented with a significantly increased risk for rupture, with $76.3 \%$ of pseudoaneurysms being ruptured. By comparison, true VAA presented with a rupture rate of $3.1 \%$. Whether beta blockers have a preventive effect is still a matter of debate [24,31]. Aneurysm calcification indicates a longstanding and therefore probably more stable aneurysm. In our series, $27.3 \%$ of non-ruptured VAAs presented with some calcification, whereas none of the ruptured cases did. Parietal thrombosis was not associated with rupture risk in our series. Patients with ruptured VAAs were slightly less likely to be taking beta blockers compared to those with non-ruptured VAAs ( $35.1 \%$ vs. $37.5 \%$, respectively). Steroid usage was slightly higher in the group of patients with ruptured VAAs.

The distribution of VAAs in our study was mostly in concordance with the literature. SAAs are reported to be the most frequent VAA; they account for up to $60 \%$ of all VAAs $[5,6]$. Bedford et al. [6] discovered $10.4 \%$ SAAs in a routine postmortem study of 250 bodies. Our data confirm that SAAs occurred with the highest frequency; SAAs accounted for $32.8 \%$ of all VAAs, with a female:male ratio of 1.2:1. Common risk factors for SAA are female gender, pregnancy and portal hypertension [21, 28]. None of our patients were pregnant, and only one was of reproductive age. Recent reports have suggested an increasing incidence of HAA, which can be attributed to the more-frequent use of CT imaging after blunt liver trauma and hepatobiliary intervention [22, 33, 34]. A total of $17.5 \%$ HAAs had a history of pancreaticoduodenectomy or biliary tract intervention. With respect to superior mesenteric artery aneurysm (SMAA) and aneurysms involving smaller branches of the coeliac trunk (gastric, pancreaticoduodenal and gastroduodenal arteries), our data are similar to that of other reports, with a $6.7 \%$ prevalence of SMAAs $([5,35]$ and $7.1 \%$ prevalence for aneurysms in branches of the coeliac axis [20]. Coeliac trunk aneurysms (CTRA) have been reported to be associated with abdominal aortic aneurysms [24], which is consistent with our data. In contrast to recent reports, we noted a strong predominance of men $(95.7 \%)$ in these cases [29]. Also in contrast to the literature, our analysis detected $18.6 \%$ CTRAs; however, most of these were characterized as degenerative lesions or poststenotic dilatation of the coeliac trunk. Only one CTRA was indicated for treatment. Stenosis is an often-described risk factor for the development of VAA of the coeliac trunk arteries 


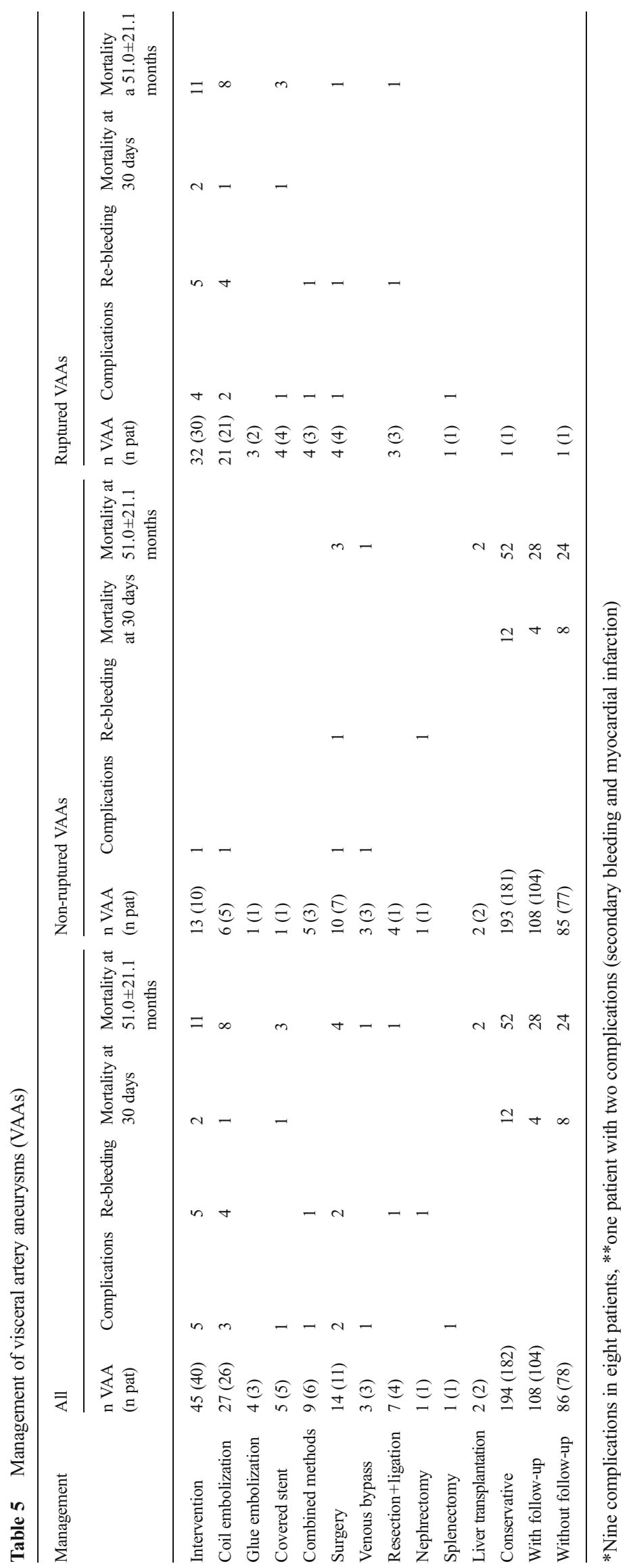


Table 6 Complications of interventional treatment

* One patient

\begin{tabular}{lllll}
\hline $\mathrm{n}$ VAA (n pat) & Complications & Re-bleeding & 30-d-mortality & Re-intervention \\
\hline Non-ruptured 13 (10) & $1(10 \%)$ & & & \\
$\quad$ Major splenic infarction & 1 & & & \\
Ruptured 32 (30) & $4(13.3 \%)$ & $5 *(16.7 \%)$ & $2(6.7 \%)$ & $2(6.7 \%)$ \\
Intracerebral haemorrhage & 1 & & 1 & \\
Myocardial infarction & $1^{*}$ & 1 & & \\
Abscess & 1 & & \\
Splenic infarction & & & \\
\hline
\end{tabular}

and SMA [4, 23, 29, 36-39], which is supported by our data. RAAs also were included in our analysis; the incidence of RAAs in our study was higher than that reported in the literature [21]. RAAs seem to be associated with fibromuscular dysplasia and medial degeneration. Hypertension is reported to be another risk factor for RAA [8, 24, 40] and was evident in $63.6 \%$ of our patients.

The favoured interventional treatment modalities for VAA include transcatheter embolization and stent grafting [24, 41]. In our analysis, embolization was performed with either pushable coils, detachable coils, glue embolic fluid, or combinations thereof, at the discretion of the investigators. Onyx liquid embolization had not yet been introduced for peripheral indications at our institution at that time. The stent grafts used were provided by various companies and were employed based on the location of the VAA, the size required, and the personal experience of the investigator. Flow diverter stents might have served as an alternative in particular cases, but they had also not yet been introduced at our institution. In contrast to open surgery, interventional procedures are normally performed under local anaesthesia, with high technical success rates [4, 20, 23, $34,41]$, low complication rates, and shorter hospital stays [31, 42]. Reported complications include technical failure to catheterize the artery [43], arterial thrombosis or embolism resulting in organ infarctions or abscesses, coil migration, aneurysm recurrence, and a haematoma or a pseudoaneurysm at the arterial puncture site [24, 27, 30, 41, 44]. Our data analysis yielded a technical success rate of $93.3 \%$ (42 of 45 aneurysms). Technical failures included one case with migration of a covered stent in an RAA, which was treated with subsequent coil embolization. In another case, coil embolization of a false RAA resulted in an incomplete occlusion, which required reintervention. In the third case, elective coil embolization of an SAA presented some coil migration, with consequent ischaemia of the spleen and pancreas.

There was a complication rate for interventional treatment of $13.3 \%$ (four complications in 30 patients) in emergency cases compared to $10 \%$ (one complication in ten patients) in elective cases. Rebleeding as a late procedural failure occurred most frequently after coil embolization. There was no mortality in elective cases but a 30-day mortality of $6.7 \%$ in emergency cases after interventional treatment, with one case of intracerebral bleeding and one patient with right heart failure after rebleeding. This is very low in comparison to other series published [4, 5, 34], only Balderi et al. [26] presented a 30-day mortality comparable to ours. Our data are, however, not suitable to achieve a comparative outcome analysis after surgical and interventional treatment. While most surgical patients received an elective operation, the majority of emergency cases were treated by means of interventional techniques. Moreover, the number of surgical cases was too small to reliably draw comparative data with respect to 30-day mortality or complication rates. The retrospective analysis of the practiced interdisciplinary decision making and the acceptable complication rates as reported above give the impression that the interventional treatment options are the treatment of choice both, in emergencies as well as in elective cases.

In conclusion, diagnoses of VAA may have increased because of increasing numbers of cross-sectional imaging studies; the incidence of SAAs was highest. We also observed significant numbers of aneurysms of the coeliac trunk arteries and renal artery, which suggests that these VAAs may be currently underdiagnosed. The mean diameter of ruptured aneurysms did not significantly differ from that of non-ruptured aneurysms. Thus, treatment indications should not be based primarily on the aneurysm diameter, but in the first instance on
Table 7 Complications of surgical treatment

\begin{tabular}{|c|c|c|c|c|}
\hline n VAA (n pat) & Complications & Re-bleeding & 30-d-mortality & Re-intervention \\
\hline Non-ruptured 10 (7) & $1(14.3 \%)$ & $1(14.3 \%)$ & & \\
\hline Insufficient anastomosis & 1 & & & \\
\hline Ruptured 4 (4) & $1(25 \%)$ & $1(25 \%)$ & & \\
\hline Splenic abscess & 1 & & & \\
\hline
\end{tabular}


the aneurysm aetiology. Pseudoaneurysms need emergency treatment. The vast majority of true aneurysms can probably be managed conservatively; however, there might be some potential for fatality due to secondary aneurysm rupture.

Acknowledgments This work contains data from the doctoral thesis of Ms. Evelyn Dappa. The scientific guarantor of this publication is M.B.Pitton. The authors of this manuscript declare no relationships with any companies, whose products or services may be related to the subject matter of the article. The authors state that this work has not received any funding. No complex statistical methods were necessary for this paper. Institutional Review Board approval was not required because of the retrospective and observational nature of the analysis. Written informed consent was not required for this study because this is a retrospective and observational analysis. No study subjects or cohorts have been previously reported. Methodology: retrospective, observational, performed at one institution

Open Access This article is distributed under the terms of the Creative Commons Attribution Noncommercial License which permits any noncommercial use, distribution, and reproduction in any medium, provided the original author(s) and the source are credited.

\section{References}

1. Belli AM, Markose G, Morgan R (2012) The role of interventional radiology in the management of abdominal visceral artery aneurysms. Cardiovasc Intervent Radiol 35:234-43

2. Abbas MA, Fowl RJ, Stone WM, Panneton JM, Oldenburg WA, Bower TC et al (2003) Hepatic artery aneurysm: factors that predict complications. J Vasc Surg 38:41-5

3. Carroccio A, Jacobs TS, Faries P, Carroccio A, Jacobs TS, Faries P et al (2007) Endovascular treatment of visceral artery aneurysms. Vasc Endovasc Surg 41:373-82

4. Gabelmann A, Görich J, Merkle EM (2002) Endovascular treatment of visceral artery aneurysms. J Endovasc Ther 9:38-47

5. Jesinger RA, Thoreson AA, Lamba R (2013) Abdominal and pelvic aneurysms and pseudoaneurysms: imaging review with clinical, radiologic, and treatment correlation. Radiographics 33:E71-96

6. Bedford PD, Logde B (1960) Aneurysm of the splenic artery. Gut 1: 312-20

7. O'Driscoll D, Olliff SP, Olliff JF (1999) Hepatic artery aneurysm. Br J Radiol 72:1018-25

8. Pfeiffer T, Reiher L, Grabitz K, Grünhage B, Häfele S, Voiculescu A et al (2003) Reconstruction for renal artery aneurysm: operative techniques and long-term results. J Vasc Surg 37:293-300

9. Liu Q, Lu JP, Wang F, Wang L, Jin AG, Wang J et al (2008) Visceral artery aneurysms: evaluation using $3 \mathrm{D}$ contrast-enhanced MR angiography. AJR Am J Roentgenol 191:826-33

10. Jana M, Gamanagatti S, Mukund A, Paul S, Gupta P, Garg P et al (2011) Endovascular management in abdominal visceral arterial aneurysms: a pictorial essay. World J Radiol 3:182-7

11. Stanson AW, Friese JL, Johnson CM, McKusick MA, Breen JF, Sabater EA et al (2001) Polyarteritis nodosa: spectrum of angiographic findings. Radiographics 21:151-9

12. Stambo GW, Guiney MJ, Cannella XF, Germain BF (2004) Coil embolization of multiple hepatic artery aneurysms in a patient with undiagnosed polyarteritis nodosa. J Vasc Surg 39:1122-4

13. Tonnessen BH, Sternbergh WC, Mannava K, Money SR (2007) Endovascular repair of an iliac artery aneurysm in a patient with Ehlers-Danlos syndrome type IV. J Vasc Surg 45:177-9
14. Naidu SG, Chong BW, Huettl EA, Stone WM (2007) Percutaneous embolization of a lumbar pseudoaneurysm in a patient with type IV Ehlers-Danlos syndrome. J Vasc Surg 46:1036-8

15. Nseir B, Cutrona AF (2009) Salmonella-related mycotic pseudoaneurysm. Cleve Clin J Med 76:315-6

16. Fielder J, Miriti K, Bird P (2010) Mycotic aneurysm of the inferior gluteal artery caused by non-typhi salmonella in a man infected with HIV: a case report. J Med Case Rep 4:273

17. Raj RK, Gandhi RT, Katzen BT (2012) Fibromuscular dysplasiarelated carotid pseudoaneurysm and pulsatile tinnitus. J Vasc Interv Radiol 23:1657

18. Memetoglu ME, Kalkan A (2012) Behcet's disease with aneurysm of internal iliac artery and percutaneous treatment. Interact Cardiovasc Thorac Surg 14:372-3

19. Gok E, Goksel OS, Alpagut U, Dayioglu E (2012) Spontaneous brachial pseudo-aneurysm in a 12-year-old with kyphoscoliosistype Ehlers-Danlos syndrome. Eur J Vasc Endovasc Surg 44:482-4

20. Hossain A, Reis ED, Dave SP, Kerstein MD, Hollier LH (2001) Visceral artery aneurysms: experience in a tertiary-care center. Am Surg 67:432-7

21. Panayiotopoulos YP, Assadourian R, Taylor PR (1996) Aneurysms of the visceral and renal arteries. Ann R Coll Surg Engl 78:412-9

22. Shanley CJ, Shah NL, Messina LM (1996) Common splanchnic artery aneurysms: splenic, hepatic, and celiac. Ann Vasc Surg 10:315-22

23. Carr SC, Mahvi DM, Hoch JR, Archer CW, Turnipseed WD (2001) Visceral artery aneurysm rupture. J Vasc Surg 33:806-11

24. Sessa C, Tinelli G, Porcu P, Aubert A, Thony F, Magne JL (2004) Treatment of visceral artery aneurysms: description of a retrospective series of 42 aneurysms in 34 patients. Ann Vasc Surg 18:695-703

25. Carmeci C, McClenathan J (2000) Visceral artery aneurysms as seen in a community hospital. Am J Surg 179:486-9

26. Balderi A, Antonietti A, Ferro L, Peano E, Pedrazzini F, Fonio $P$ et al (2012) Endovascular treatment of visceral artery aneurysms and pseudoaneurysms: our experience. Radiol Med 7

27. Cochennec F, Riga CV, Allaire E, Cheshire NJ, Hamady M, Jenkins MP et al (2011) Contemporary management of splanchnic and renal artery aneurysms: results of endovascular compared with open surgery from two European vascular centers. Eur J Vasc Endovasc Surg 42:340-6

28. Nosher JL, Chung J, Brevetti LS, Graham AM, Siegel RL (2006) Visceral and renal artery aneurysms: a pictorial essay on endovascular therapy. Radiographics 26:1687-704, quiz 1687

29. Pasha SF, Gloviczki P, Stanson AW, Kamath PS (2007) Splanchnic artery aneurysms. Mayo Clin Proc 82:472-9

30. Salam TA, Lumsden AB, Martin LG, Smith RB (1992) Nonoperative management of visceral aneurysms and pseudoaneurysms. Am J Surg 164:215-9

31. Abbas MA, Stone WM, Fowl RJ, Gloviczki P, Oldenburg WA, Pairolero PC et al (2002) Splenic artery aneurysms: two decades experience at mayo clinic. Ann Vasc Surg 16:442-9

32. Dawson J, Fitridge R (2013) Update on aneurysm disease: current insights and controversies: peripheral aneurysms: when to intervene is rupture really a danger? Prog Cardiovasc Dis 56:26-35

33. Sueyoshi E, Sakamoto I, Nakashima K, Minami K, Hayashi K (2005) Visceral and peripheral arterial pseudoaneurysms. AJR Am J Roentgenol 185:741-9

34. Tulsyan N, Kashyap VS, Greenberg RK, Sarac TP, Clair DG, Pierce G et al (2007) The endovascular management of visceral artery aneurysms and pseudoaneurysms. J Vasc Surg 45:276-83, discussion 283

35. Kopatsis A, D'Anna JA, Sithian N, Sabido F (1998) Superior mesenteric artery aneurysm: 45 years later. Am Surg 64:263-6

36. Lykoudis PM, Stafyla VK, Koutoulidis V, Xatziioannou A, Arkadopoulos N, Mourikis I et al (2012) Stenting of a gastroduodenal artery aneurysm: report of a case. Surg Today 42:72-4

37. Gouny P, Fukui S, Aymard A, Decaix B, Mory H, Merland JJ et al (1994) Aneurysm of the gastroduodenal artery associated with stenosis of the superior mesenteric artery. Ann Vasc Surg 8:281-4 
38. Brocker JA, Maher JL, Smith RW (2012) True pancreaticoduodenal aneurysms with celiac stenosis or occlusion. Am J Surg

39. Granke K, Hollier LH, Bowen JC (1990) Pancreaticoduodenal artery aneurysms: changing patterns. South Med J 83:918-21

40. Morita K, Seki T, Iwami D, Sasaki H, Fukuzawa N, Nonomura K (2012) Long-term outcome of single institutional experience with conservative and surgical management for renal artery aneurysm. Transplant Proc 44:1795-9

41. Chiesa R, Astore D, Guzzo G, Frigerio S, Tshomba Y, Castellano R et al (2005) Visceral artery aneurysms. Ann Vasc Surg 19:42-8
42. Carr SC, Pearce WH, Vogelzang RL, McCarthy WJ, Nemcek AA, Yao JS (1996) Current management of visceral artery aneurysms. Surgery 120:627-33, discussion 633-4

43. Kasirajan K, Greenberg RK, Clair D, Ouriel K (2001) Endovascular management of visceral artery aneurysm. J Endovasc Ther 8:150-5

44. Skipworth JR, Morkane C, Raptis DA, Kennedy L, Johal K, Pendse $\mathrm{D}$ et al (2011) Coil migration: a rare complication of endovascular exclusion of visceral artery pseudoaneurysms and aneurysms. Ann R Coll Surg Engl 93:e19-23 